www.jmscr.igmpublication.org

Impact Factor 5.84

Index Copernicus Value: 71.58

ISSN (e)-2347-176x ISSN (p) 2455-0450

crossref DOI: _https://dx.doi.org/10.18535/jmscr/v5i12.17

Journal Of Medical Science And Clinical Research

\title{
Study of Serial Serum Sodium Values in Decompensated Liver Disease Patients during the Phase of Hepatic Encephalopathy
}

\author{
Authors \\ Gurusamy Gurunamasivayam $^{1}$, Arunkumar Jayakumar ${ }^{2}$ \\ Santhi Thoppappatty Sengottaiyan ${ }^{3}$, Palani Kannan ${ }^{4}$
}

${ }^{1}$ Senior Assistant Professor of Medicine, Govt. Kilpauk Medical College, Chennai, India

${ }^{2,4}$ Resident, Govt. Kilpauk Medical College, Chennai, India

${ }^{3}$ Associate Professor of Medicine, Govt. Kilpauk Medical College, Chennai, India

Corresponding Author

Gurusamy Gurunamasivayam

Senior Assistant Professor of Medicine, Govt. Kilpauk Medical College, Chennai, India

Email: sudhagurul@gmail.com, Tel: 9443330384

\begin{abstract}
Background: Hepatic encephalopathy is a dreaded complication of chronic liver disease patients in the decompensated state, associated with high percentage of mortality. Decompensated liver disease is associated with lower serum sodium values than compensated liver disease, though grading of hepatic encephalopathy scales are available, they are clinical and subjective to variation in the clinicians examination.

Aim: This study was done in order to study the corroboration of serum sodium values with various grades of hepatic Encephalopathy and to see the utility of serial serum sodium values as prognostic indicator in the outcome of patients with decompensated liver disease with hepatic Encephalopathy.

Materials and Methods: Study design planned is a Descriptive, case control study. Cases were obtained from the intensive care unit of Govt. Kilpauk Medical college. Controls were enrolled from the outpatient department. The patients with h/o chronic liver disease presenting in decompensated state in Hepatic encephalopathy as per West Haven criteria will be included in the study Patients who are in Hepatic encephalopathy Stage 2-4 are taken. The patients who are in hepatic encephalopathy will be studied from the time of admission for duration of 2 weeks to assess whether they are improving or not. Serial monitoring of the blood parameters will be done tabulated and compared to assess the variation of serum sodium levels during the period of two weeks. At the end of two weeks the mean serum sodium values between those in Hepatic encephalopathy (Grade 2-4) and those in the controls with no or early Hepatic Encephalopathy will be compared.

Results: It is evident that there is an improvement in the mean Serum sodium values from Day 1 to Day 14 in the cases. There is also a shift in the clustering of cases with hepatic encephalopathy from higher grades (4-3) to lower grades $(2-1)$ during the course of the study. When the cases and controls were compared there is a significant difference in the fluctuations of the serum sodium levels from day 1 to day 14 in the cases when compared to the control. In both the above statistical tools the probability value 0.05 is considered as significant level.

Conclusion: If not an absolute indicator and also with the lack of high end investigations serum sodium values may serve to be an easily accessible tool to assess the initial condition of patients with hepatic encephalopathy. In resource deficient settings and in physician assessment with conflicting status of the patient, serum sodium may help assess the response to treatment.

Keywords: Hepatic Encephalopathy, Decompensated Liver Disease, West Haven Criteria, Hyponatremia
\end{abstract}




\section{Introduction}

Serum sodium variations are a common electrolyte abnormality encountered in patients with Chronic liver disease and more so when they develop overt Hepatic encephalopathy.

Hepatic encephalopathy is one of the dreaded complications of chronic liver disease. A majority of patients with ethanol related chronic liver disease progress to the decompensated state thereby developing Hepatic encephalopathy either due to continued ethanol consumption, superadded infection or blood loss etc.

Analysis of the course and variation in the Biochemical parameters during the disease process might help in the better understanding and management of the disease process.

In chronic liver disease owing to hepatic dysfunction patients develop Hypoproteinaemia and thereby also progress to a state of fluid overload leading to dilutional Hyponatraemia. As a feature of worsening hepatic dysfunction patients develop Hepatic encephalopathy due to failure of degradation activity of the liver leading to accumulation of toxic metabolites. Serum sodium levels in previous studies have shown to be worse in Decompensated state when compared to compensated chronic liver disease.

This study has been done to observe the fluctuations of serum sodium values in various Grades of Hepatic encephalopathy and also in patients with chronic liver disease, to ascertain the use of serum sodium as an indicator to the severity of Hepatic encephalopathy and to observe the nominal Variations in patients with Chronic liver disease without the complication.

\section{Aim}

This study was done in order to study the corroboration of serum sodium values with various grades of hepatic Encephalopathy and to see the utility of serial serum sodium values as prognostic indicator in the outcome of patients with decompensated liver disease with hepatic Encephalopathy.

\section{Materials and Methods}

Study design planned is a Descriptive, case control study. Cases were obtained from the intensive care unit of Govt. Kilpauk Medical college. Controls were enrolled from the outpatient department.

Chronic liver disease patients presenting in Decompensated state and getting admitted in the Medicine Department with diagnosis of Hepatic Encephalopathy (Grade 2 - 4) at Govt Kilpauk Medical College, Chennai.

Control patients will be chronic Liver disease patients attending the Outpatient Department not in Hepatic encephalopathy. The estimated prevalence of Hyponatraemia (Serum sodium $\leq$ $130 \mathrm{mEq} / \mathrm{L}$ ) is $70 \%$ in Hepatic encephalopathy associated with DCLD, with $95 \%$ confidence level and with absolute variability of $20 \%, 83$ cases of diagnosed Hepatic encephalopathy will be included in the study. The patients being enrolled into the study were the In-patients admitted in the ICU with diagnosis as Hepatic encephalopathy Grade 2-4 (as per West Haven criteria).

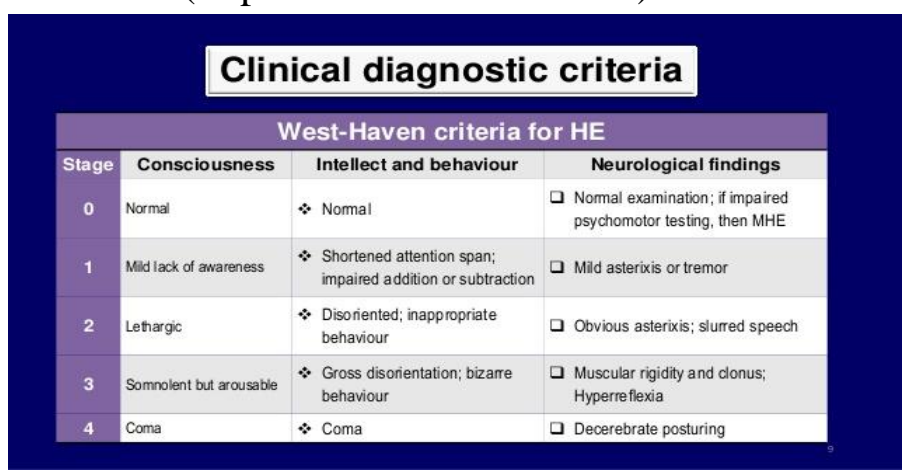

Control patients will be previously diagnosed Chronic liver Disease patients attending the OPD. The Patients with acute intracerebral events like infarct or haemorrhage, patients in sepsis with positive blood cultures that may contribute to the encephalopathy, H/o drug intake such as diuretics, narcotics, valproic acid, patients developing hepatorenal syndrome were excluded from the study. The patients with h/o chronic liver disease presenting in decompensated state in Hepatic encephalopathy as per West Haven criteria will be included in the study Patients who are in Hepatic encephalopathy Stage 2-4 are taken. 
The patients who are in hepatic encephalopathy will be studied from the time of admission for duration of 2 weeks to assess whether they are improving or not. Blood samples will be collected and analysed for the levels for serum sodium, Creatinine, Bilirubin, Blood Urea and Total count. Serial monitoring of the blood parameters will be done tabulated and compared to assess the variation of serum sodium levels during the period of two weeks. $4 \mathrm{ml}$ of blood will be collected and segregated into three vacuum tubes. One tube with $2 \mathrm{ml}$ of blood will be sent to the Department of Biochemistry Govt Kilpauk Medical College (GKMC) for analysis of serum sodium, blood urea and serum creatinine. $1 \mathrm{ml}$ of blood will be used to ascertain the serum bilirubin levels which will also be analysed in the Department of Biochemistry GKMC. $1 \mathrm{ml}$ of blood with EDTA will be analysed in Pathology department GKMC for total count

Serum sodium levels will be analysed every three days, rest of the parameters will be analysed on a weekly basis. Control will be CLD patients, their serum sodium levels will be analysed for the same duration of two weeks, blood samples being collected on weekly basis.

Analysis of patients admitted with hepatic encephalopathy will be followed up with respect to their serum sodium values. Patient's condition improving or deteriorating will be analysed as per the West Haven Criteria and either an increase or decrease in the serum sodium will be followed up indicating the prognostic value of serum sodium level. Control patients attending the OPD will be enrolled and their serum sodium values followed up to monitor any fluctuations. At the end of two weeks the mean serum sodium values between those in Hepatic encephalopathy (Grade 2-4) and those in the controls with no or early Hepatic Encephalopathy will be compared.

The study group consists of

1. Patients diagnosed to have hepatic encephalopathy whose serum sodium is studied every 3 days. (CASES)
2. Outpatients with Chronic liver disease attending the Hospital for serum sodium every week. (CONTROLS)

They are studied for a period of two weeks. The collected data were analysed with IBM. SPSS statistics software 23.0 version. To describe about the data descriptive statistics frequency analysis, percentage analysis were used for categorical variables and the mean \& S.D were used for continuous variables. To find the significant difference in the repeated measures, the repeated measures of ANOVA with adjustment for multiple comparisons to control the type I error, the Bonferroni test is used for normal data and Friedmam test is used for skewed data. In both the above statistical tools the probability value 0.05 is considered as significant level.

\section{Results}

Fig 1: Gender distribution of cases

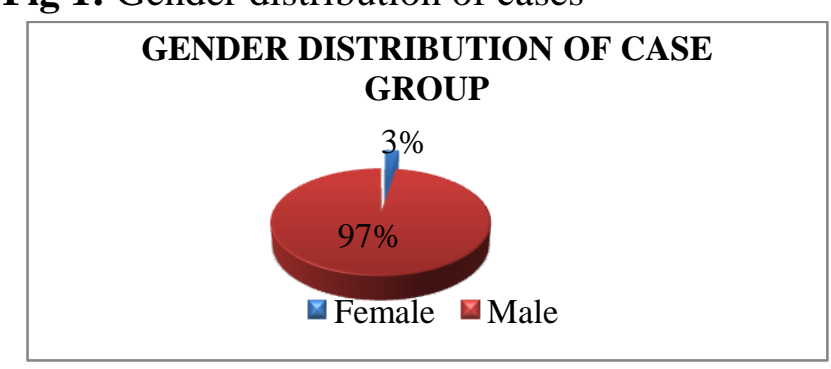

Fig 2: Gender Distribution of Controls

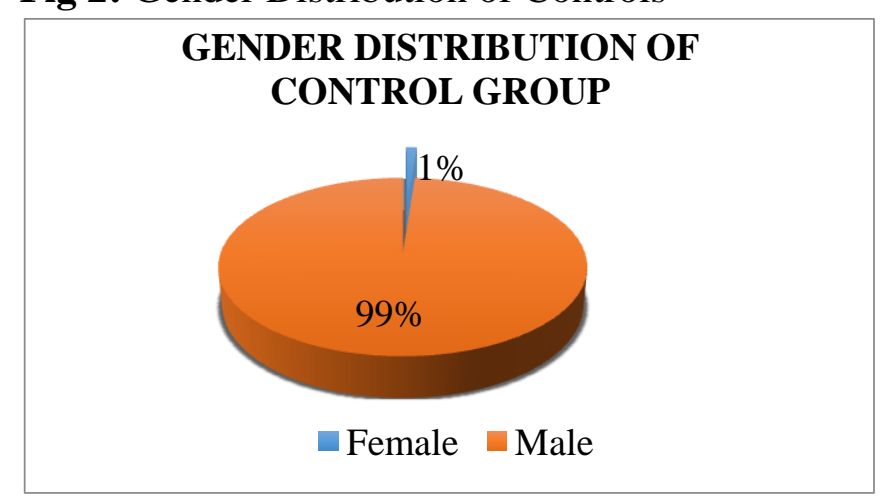

Table 1: Mean Serum Sodium Values Of Cases with Median Clinical West Haven Criteria

\begin{tabular}{|l|c|c|c|c|}
\hline $\begin{array}{l}\text { S1 } \\
\text { No }\end{array}$ & Days & $\begin{array}{c}\text { Mean Serum } \\
\text { Sodium } \pm \text { S.D }\end{array}$ & $\begin{array}{c}\text { West Haven } \\
\text { Criteria }\end{array}$ & $\begin{array}{c}\mathrm{p} \\
\text { value }\end{array}$ \\
\cline { 1 - 3 } 1 & Day 1 & $124.5 \pm 3.6$ & 4 & \multirow{3}{*}{.0005} \\
\hline 2 & Day3 & $125.1 \pm 3.0$ & 4 & \\
\hline 3 & Day 6 & $125.7 \pm 2.9$ & 4 & \\
\hline 4 & Day 9 & $126.8 \pm 3.2$ & 3 & \\
\hline 5 & Day 12 & $127.2 \pm 3.4$ & 3 & \\
\hline 6 & Day 14 & $128.3 \pm 3.8$ & 2 & \\
\hline
\end{tabular}


Graph 1 Median West Haven Critera Score

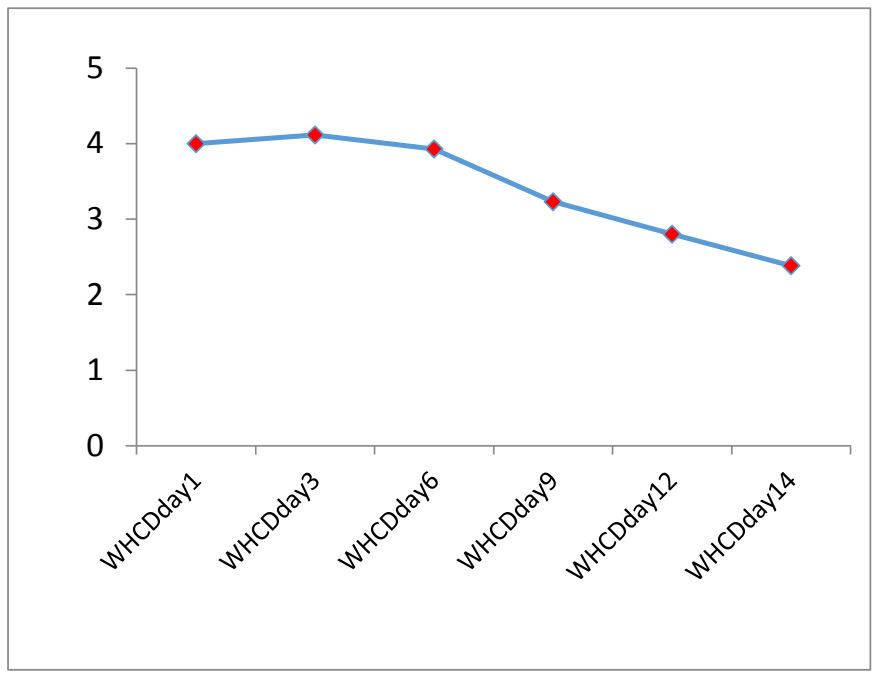

Graph 2: Mean Serum sodium values from Day 1 through Day 14

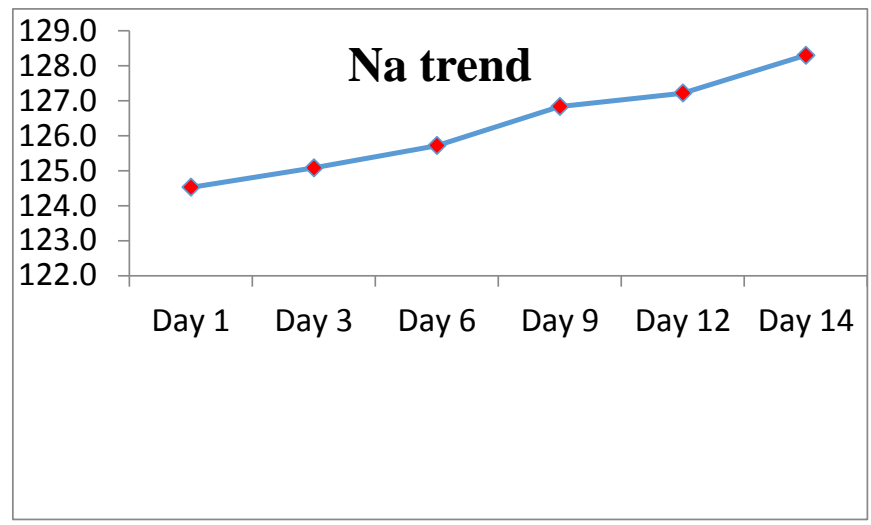

The above line diagram shows that As the Mean serum sodium Values are improving the relative number of patients with higher Grade s of Hepatic encephalopathy are decreasing to a lower grade.

The line diagram showed in a and $b$ depict that the general mean of the patients in the initial days of the study with lower mean serum sodium levels were seen to have more severe grade s of Hepatic encephalopathy.

Table 2: Showing Mean Serum sodium values of subjects in controls

\begin{tabular}{|l|c|c|c|c|}
\hline $\begin{array}{l}\text { Sl } \\
\text { no }\end{array}$ & Day & $\begin{array}{c}\text { Mean serum } \\
\text { Sodium }\end{array}$ & $\begin{array}{c}\text { Standard } \\
\text { Deviation }\end{array}$ & $\begin{array}{c}\text { West Haven } \\
\text { Criteria }\end{array}$ \\
\hline 1 & 1 & 132.38 & 2.386 & Not applicable \\
\hline 2 & 6 & 132.66 & 2.616 & Not applicable \\
\hline 3 & 14 & 133.07 & 2.689 & Not applicable \\
\hline
\end{tabular}

The fluctuation about the mean serum sodium values of patients in the controls is not significant and they did not show any signs of Heptic Encephalopathy and hence are not given a scoring as per West Haven Criteria.
Table 3: Serum sodium and the relative percentage of patients within each range

\begin{tabular}{|l|c|c|c|c|c|c|c|}
\hline $\begin{array}{l}\text { Sl } \\
\text { No }\end{array}$ & $\begin{array}{c}\text { Serum } \\
\text { Sodium } \\
(\mathrm{mEq} / \mathrm{L})\end{array}$ & $\begin{array}{c}\text { Day } \\
1\end{array}$ & $\begin{array}{c}\text { Day } \\
4\end{array}$ & $\begin{array}{c}\text { Day } \\
6\end{array}$ & $\begin{array}{c}\text { Day } \\
9\end{array}$ & $\begin{array}{c}\text { Day } \\
12\end{array}$ & $\begin{array}{c}\text { Day } \\
14\end{array}$ \\
\hline 1 & $<120$ & & & 3.8 & 7.7 & 12.8 & 30.8 \\
\hline 2 & $121-125$ & 44.9 & 55.1 & 56.4 & 64.1 & 61.5 & 50.0 \\
\hline 3 & $126-130$ & 41 & 37.2 & 33.3 & 23.1 & 23.1 & 14.1 \\
\hline 4 & $>130$ & 14.1 & 7.7 & 6.4 & 5.1 & 2.6 & 5.1 \\
\hline
\end{tabular}

Graph 3- Pictorial representation of patients serum sodium values

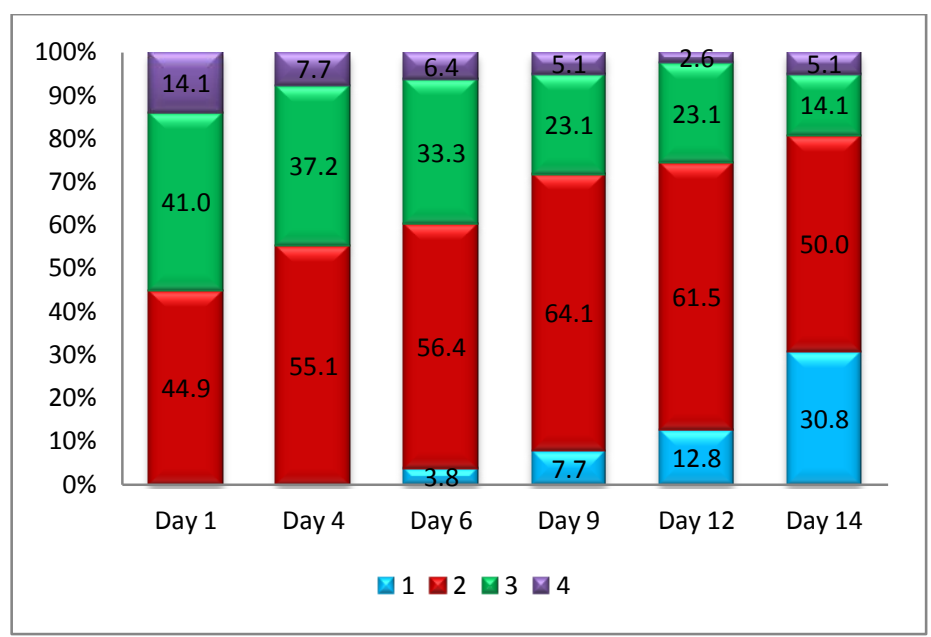

Serum sodium values 1->130, 2-126-130, 3 -121$125,4-<120$

Table 4: Relative percentage of patients in Hepatic Encephalopathy as per West Haven Criteria

\begin{tabular}{|l|c|c|c|c|c|c|}
\hline WHC & Day1 & Day3 & Day6 & Day9 & Day12 & Day14 \\
\hline 1 & & & & 2.6 & 11.5 & 26.9 \\
\hline 2 & 26.9 & 43.6 & 50.0 & 69.2 & 64.1 & 52.6 \\
\hline 3 & 69.2 & 51.3 & 44.9 & 23.1 & 20.5 & 15.4 \\
\hline 4 & 3.8 & 5.1 & 5.1 & 5.1 & 3.8 & 5.1 \\
\hline
\end{tabular}

Graph 4: Patients with various grades of Hepatic Encephalopathy

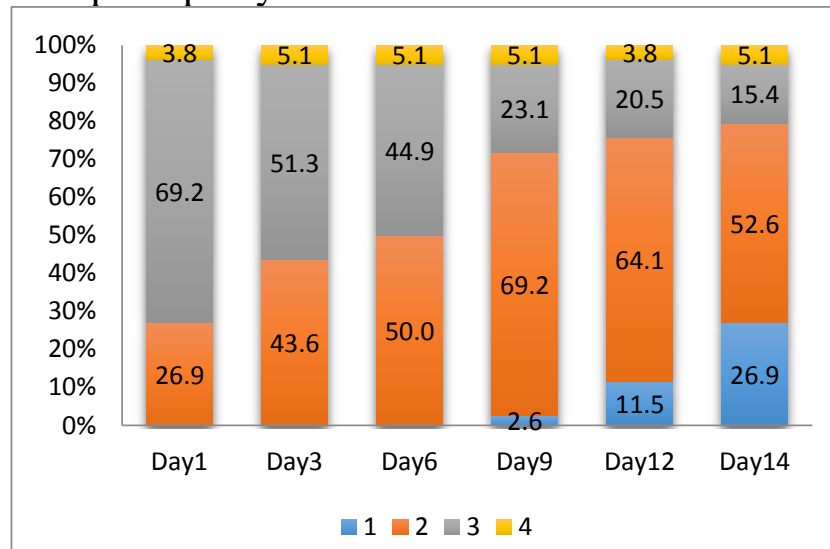

$1-$ WHC grade $1,2-$ WHC grade $2,3-W H C$ grade 3,4 - WHC grade 4 
We now compare the serum Sodium values of the patients in the Cases and Controls on Days 1, 6 and 14.

Table 5 : Showing Mean Serum Sodium values on days 1,6 and 14 in HE Cases and Controls

\begin{tabular}{|c|c|c|c|c|}
\hline \multicolumn{2}{|c|}{ VAR00001 } & $\mathrm{N}$ & Mean \pm S.D & p value \\
\hline \multirow{2}{*}{ Naday1 } & Exp & 78 & $124.53 \pm 3.6$ & \multirow{2}{*}{.0005} \\
\cline { 2 - 5 } & Con & 81 & $132.42 \pm 2.3$ & \\
\hline Naday6 & Exp & 78 & $125.72 \pm 2.9$ & \multirow{2}{*}{.0005} \\
\cline { 2 - 4 } & Con & 81 & $132.69 \pm 2.6$ & \\
\hline Naday14 & Exp & 78 & $128.29 \pm 3.8$ & \multirow{2}{*}{.0005} \\
\cline { 2 - 4 } & Con & 81 & $133.11 \pm 2.6$ & \\
\hline
\end{tabular}

Table 6: Independent Samples Test of sodium from Day 1 to 14

As The $\mathrm{p}$ value was found to be $<.005$ there is a significant statistical difference on comparing the

\begin{tabular}{|c|c|c|c|c|c|}
\hline & & Mean & S.D & t-Value & P-Value \\
\hline \multirow{2}{*}{ Naday1 } & Exp & 124.5 & 3.7 & \multirow{2}{*}{16.042} & \multirow{2}{*}{$0.0005 * *$} \\
\hline & Con & 132.4 & 2.4 & & \\
\hline \multirow{2}{*}{ Naday6 } & Exp & 125.7 & 3.0 & \multirow{2}{*}{15.64} & \multirow{2}{*}{$0.0005 * *$} \\
\hline & Con & 132.7 & 2.6 & & \\
\hline \multirow{2}{*}{ Naday14 } & Exp & 128.3 & 3.9 & \multirow{2}{*}{9.11} & \multirow{2}{*}{$0.0005 * *$} \\
\hline & Con & 133.1 & 2.7 & & \\
\hline
\end{tabular}

serum sodium levels of patients on the 1, 6 and 14 day thereby we can infer that the fluctuations in the serum sodium levels are due to the hepatic encephalopathy, as there is no similar significant fluctuation in the serum sodium values in the control group on the same study days.

Figure 5: Line diagram showing serum sodium levels during study period

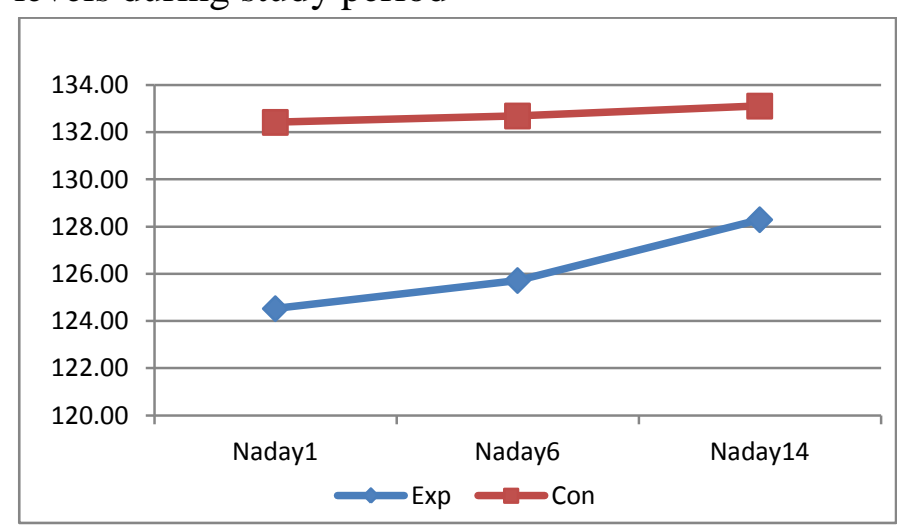

While in the controls, where the mean serum sodium values show more or less a linear variation, in the cases there is a significant fluctuation of the serum sodium values over the period of study. As majority of patients in the Cases showed an improvement in the serum sodium values it is up sloping.

\section{Discussion}

The relation between Serum sodium values and Hepatic encephalopathy have been studied in the past, apart from the contributory effect of lower serum sodium values to Hepatic encephalopathy, it has also been observed that there is a general rise in the serum sodium values with the improvement in the Grade of Hepatic encephalopathy. The purpose of the study was to observe the serum sodium levels in patients with severe Hepatic encephalopathy during the course of treatment. To see the fluctuations in the serum sodium levels in cases with Hepatic encephalopathy admitted with those patients with chronic liver disease attending the outpatient department over a period of two weeks. To see if the variations in the serum sodium levels were a consequence of disease activity and severity. The shortcomings of the study were that during the course of the study there were a few patients who had very severe disease and could not be saved and such patients could not be taken up for analysis. The study is done on patients who had developed liver disease with etiology of ethanol consumption. The various modalities of treatment of each patient were individualized and the exact treatment protocol for the entire cases could not be standardized.

Nearly 80 patients were studied in the cases and it revealed that majority of the patients were within the $36-55$ years age group, accounting for nearly $90 \%$ of patients. There was a general male preponderance with nearly $97 \%$ of the total cases. This can be attributed to the fact that at present the prevalence of alcoholism is more in the male than the female in the general population.

From the cases it could be seen that patients with Hepatic Encephalopathy generally had serum sodium values less than $130 \mathrm{mEq} / \mathrm{L}$. Patients with 
higher Grades of hepatic encephalopathy had lower Serum Sodium values.

It is evident that there is an improvement in the mean Serum sodium values from Day 1 to Day 14 in the cases. There is also a shift in the clustering of cases with hepatic encephalopathy from higher grades (4-3) to lower grades $(2-1)$ during the course of the study. Even though the exact one to one relationship between serum sodium and grades of hepatic encephalopathy could not be established, the serial monitoring of patients revealed that there is an increase in the serum sodium levels of patients with improvement of the hepatic encephalopathy. When the cases and controls were compared there is a significant difference in the fluctuations of the serum sodium levels from day 1 to day 14 in the cases when compared to the control. The patients in the control had more constant serum sodium values during the period of study. With further research into the association between serum sodium levels and the severity of hepatic encephalopathy, serum sodium levels might turn out to be a novel marker to assess the severity and prognosis of patients in hepatic encephalopathy. In resource limiting areas as is observed in many parts of rural India, where a majority of patients first come into contact with the health system, serial serum sodium measurement will help to assess patients who are stable, who are deteriorating or on the verge of progressive disease and the need for prompt referral which might also help reduce the burden of excessive referrals to tertiary care centres.

\section{Conclusion}

Patients with severe grades of hepatic encephalopathy had lower Serum Sodium values. The study population had a large number of male patients developing the disease and the complication. As majority of the patients improved during the course of the study they progressed from higher grades to lower grades of hepatic encephalopathy accompanied with an improvement in the serum sodium values. Patients with chronic liver disease without complications had less variable serum sodium values when compared with patients with hepatic encephalopathy.

If not an absolute indicator and also with the lack of high end investigations serum sodium values may serve to be an easily accessible tool to assess the initial condition of patients with hepatic encephalopathy. In resource deficient settings and in physician assessment with conflicting status of the patient, serum sodium may help assess the response to treatment.

\section{Acknowledgement}

We the authors sincerely thank the participants, staffs, paramedics and statistician for their cooperation and their contribution towards this study.

\section{Conflict of interest}

All authors contributed equally in developing the manuscript.

\section{References}

1. Weissenborn K, Heidenreich S, Giewekemeyer K, Rückert N, Hecker H. Memory function in early hepatic encephalopathy. $J$ Hepatol 2003; 39:320-325.

2. Prasad S, Dhiman RK, Duseja A, Chawla YK, Sharma A, Agarwal R. Lactulose improves cognitive functions and healthrelated quality of life in patients with cirrhosis who have minimal hepatic encephalopathy. Hepatology 2007; 45:549-559.

3. Dhiman R, Saraswat VA, Sharma BK, et al. Minimal hepatic encephalopathy: consensus statement of a working party of the Indian National Association for study of the liver. J GastroenterolHepatol 2010; 25:1029-1041.

4. Bahceci F, Yildirim B, Karincaoglu M, Dogan I, Sipahi B. Memory impairment in patients with cirrhosis. J Natl Med Assoc 2005; 97:213-216.

5. Meyer T, Eshelman A, Abouljoud M. Neuropsychological changes in a large 
sample of liver transplant candidates. Transplant Proc 2006; 38:3559-3660.

6. Binesh N, Huda A, Thomas MA, et al. Hepatic encephalopathy: a neurochemical, neuroanatomical, and neuropsychological study [published online ahead of print February 15, 2006]. J ApplClin Med Phys 2006; 7:8696. doi:10.1120/jacmp.v7i1.2151

7. Mattarozzi K, Stracciari A, Vignatelli L, D’Alessandro R, Morelli MC, Guarino M. Minimal hepatic encephalopathy: longitudinal effects of liver transplantation. Arch Neurol 2004; 61:242-247.

8. Kügler CF, Petter J, Taghavy A, et al. Dynamics of cognitive brain dysfunction in patients with cirrhotic liver disease: an event-related P300 potential perspective. Electroencephalogr Clin Neurophysiol 1994; 91:33-41.

9. Bajaj JS, Thacker LR, Heuman DM, et al. The Stroop smartphone application is a short and valid method to screen for minimal hepatic encephalopathy [published online ahead of print May 23, 2013]. Hepatology 2013; 58:1122-1132. doi:10.1002/hep.26309

10. Stroop JR. Studies of interference in serial verbal reactions. J ExpPsychol 1935; 18:643-662.

11. Blei AT, Córdoba J; Practice Parameters Committee of the American College of Gastroenterology. Hepatic encephalopathy. Am J Gastroenterol 2001; 96:19681976.

12. Mas A, Rodés J, Sunyer L, et al; Spanish Association for the Study of the Liver Hepatic Encephalopathy Cooperative Group. Comparison of rifaximin and lactitol in the treatment of acute hepatic encephalopathy: results of a randomized, double-blind, double-dummy, controlled clinical trial. J Hepatol 2003; 38:51-58.
13. Bass NM, Mullen KD, Sanyal A, et al. Rifaximin treatment in hepatic encephalopathy. N Engl J Med 2010; 362:10711081.

14. Sharma BC, Sharma P, Lunia MK, Srivastava S, Goyal R, Sarin SK. A randomized, double-blind, controlled trial comparing rifaximin plus lactulose with lactulose alone in treatment of overt hepatic encephalopathy [published online ahead of print July 23, 2013]. Am J Gastroenterol 2013; 108:1458-1463. doi:10.1038/ajg.2013.219

15. Chetri K, Choudhuri G. Role of trace elements in hepatic encephalopathy: zinc and manganese. Indian $J$ Gastroenterol 2003; 22(suppl 2):S28-S30. 